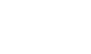

SOME PROBLEMS AND ADVANCES

IN THE STATE-OF-THE-ART IN THE ANALYSIS OF

THE WOOD RIVER JUNCTION, RHODE ISLAND

ACCIDENTAL CRITICALITY EXCURSION

M. M. Shapiro

F. Nakache

H. Soodak

delivered at

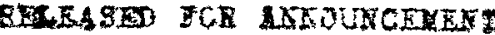

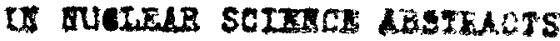

Tenth Annual Meeting Health Physics Society

Los Angeles, California

June 16, 1965

\title{
UNITED NUCLEAR
}


$\mathrm{RD}-3061$

SOME PROBLEMS AND ADVANCES IN THE STATE-OF-THE-ART IN THE ANALYSIS OF THE WOOD RIVER JUNCTION, RHODE ISLAND ACCIDENTAL CRITICALITY EXCURSION

M. M. Shapiro

F. Nakache

H. Soodak

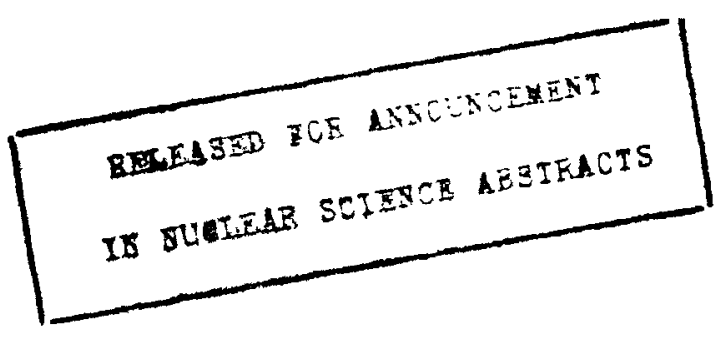

delivered at

Tenth Annual Meeting Health Physics Society

Los Angeles, California June 16, 1965

This document is

PUBLICLY RELEASABLE thesh finew

Authorizing Ofincial

Date: 


\section{DISCLAIMER}

This report was prepared as an account of work sponsored by an agency of the United States Government. Neither the United States Government nor any agency Thereof, nor any of their employees, makes any warranty, express or implied, or assumes any legal liability or responsibility for the accuracy, completeness, or usefulness of any information, apparatus, product, or process disclosed, or represents that its use would not infringe privately owned rights. Reference herein to any specific commercial product, process, or service by trade name, trademark, manufacturer, or otherwise does not necessarily constitute or imply its endorsement, recommendation, or favoring by the United States Government or any agency thereof. The views and opinions of authors expressed herein do not necessarily state or reflect those of the United States Government or any agency thereof. 


\section{DISCLAIMER}

Portions of this document may be illegible in electronic image products. Images are produced from the best available original document. 
Last July an accidental criticality occurred at the Wood River Junction, Rhode Island plant of the United Nuclear Corporation. One employee was exposed to lethal radiation and died approximately 48 hours after the incident. Two other employees were exposed in excess of the maximum permissible quarterly dose and three other employees were exposed to minor amounts of radiation. As a result of the accident, operations in the plant were suspended for five months. During this time an investigation team with members representing all divisions of the Corporation investigated thoroughly the conditions leading up to the incident, and analyzed exhaustive1y the nuclear physics and dosimetry aspects of the accident. In addition, the Atomic Energy Commission appointed a six man technical review committee which met with company personnel and conducted an independent investigation. The plant resumed normal operations in December, after company management had convinced itself and assured the Division of Licensing and Regulation that the plant could be operated safely.

Prior to beginning the decontamination and cleanup, the investigating team made a thorough survey of the entire plant to observe the conditions left by the incident. They took many photographs and collected samples from all the jars and bottles located in that portion of the plant where the incident occurred. Coins from the pockets of plant personnel, a watch, and samples of metallic material from the room where criticality occurred were collected for activation analysis. The decontamination effort was controlled so that no pertinent evidence was destroyed. No uraniumbearing material was moved in the plant until its relevance to the incident had been established. 
The two most difficult tasks tackled by the investigating team were the establishment of what exactly had happened from a nuclear physics point of view, and the determination of the doses received by two of the plant personnel who had reentered the area following the initial criticality accident. Owing to the death of the principal person involved, the conditions relating to the establishment of criticality were almost completely unknown. The chemical composition and strengths of the non-process solutions, whose mixing led to the criticality, were not precisely known at the time of the incident. Initial analysis of data from independent laboratories produced gross inconsistencies. There is no time in this brief paper to describe the unravelling of the several puzzles and the resolution of the inconsistencies. Instead, I shall merely give you the results of that investigation and concentrate today on the equally important problems relating to personnel dosimetry. Here it was necessary to make use of all of the techniques developed as a result of other accidents and, in addition, to break new ground in the interpretation of thermal neutron activation measurements in order to obtain consistent doses from the different sources of data.

First, let me tel1 you what happened. The plant located in Wood River Junction is operated exclusively for the recovery of enriched uranium from cold scrap. The plant is designed and equipped to recover uranium from acid solutions, aluminum and zirconium alloys, ceramics, and miscellaneous burnables. The plant had been licensed in March 1964 and, therefore, had been in operation only 
a few months when the accident occurred. During this entire period the plant worked exclusively on recovering uranium from dilute pickle liquor solutions, generated in the Fuels Division of the company. At one stage of the process a dilute aqueous solution of uranyl nitrate is concentrated by evaporating off some of the water. On the midnight to 8:00 am shift on the day before the accident, the evaporator ceased to function. On the next shift, the evaporator was shut down, disassembled, and found to be plugged with solid uranyl nitrate. This material was removed, dissolved in water, and put into 11-1iter bottles. Criticality safety was maintained by using only safe-geometry containers for all stages of the transfer.

Trichloroethane is used in the extraction process. This solvent, known as TCE, gradually becomes contaminated with 400 to $800 \mathrm{ppm}$ of uranium and has to be cleaned up. The procedure for washing or cleaning TCE consists of bringing it into contact with an aqueous solution of sodium carbonate. The uranium goes into the water phase which floats on top of the dense TCE. Plant operating procedure called for this operation to take place in 11-1iter, safe-geometry bottles, by manually shaking or rocking the bottle. However, one week before the accident an operator first used a large steel tank and an electric mixer to perform this operation of cleaning TCE, providing the TCE analyzed less than 800 ppm of uranium.

The cleaning out of the evaporator generated three bottles of highly concentrated uranyl nitrate solutions. This was the 
first time in the operation of the plant that such highly concentrated solutions had ever been put into 11-liter bottles. The bottle involved in the accident was labelled concentrated liquor* from evaporator. It was put in a bird-cage cart and moved to a storage area. Yellow stanchions connected by a yellow rope were placed around this bottle as a special precaution because it contained concentrated uranium solution.

The victim of the accident died without leaving a clear understanding of what exactly he did and, most puzzling, why he did it. Sometime around 6:00 pm, this operator asked his supervisor whether he should clean some TCE. He was told that there was no need to wash any TCE that evening. Nevertheless, he set out either to wash some TCE or to obtain an empty bottle, which he could only do by emptying TCE from one of them. He apparently went to the storage area and took a bottle, clearly labelled to contain concentrated uranium solution, from behind the yellow stanchions connected by a yellow rope, out of its bird-cage cart. This bottle contained 2800 grams of highly enriched uranium in aqueous solution. He proceeded to pour this into the stainless steel tank containing 41 liters of sodium carbonate solution. When he had nearly finished pouring, an excursion of approximately $10^{17}$ fissions occurred. The first slide shows a picture of the room in which the accident occurred. The 1/4 HP electrical stirrer can be seen mounted on the tank. The 11-liter plastic bottle is lying on the floor. The small diameter assures against criticality.

The fission products decomposed water to form large quantities of hydrogen and oxygen. This radiolytic gas ejected

* plant terminology for uranium solution. 
10 to 11 liters of solution from the tank and left 2 kilograms of uranium in the tank, dissolved in about 40 liters of liquid. During most of the next hour and three-quarters the tank was subcritical.

One and three-quarters hours after the incident, the plant superintendent and the supervisor entered the building and went to the third floor room where the accident occurred. Their pur. pose was to drain the contents of the tank into safe-geometry containers in order to assure that further incidents would not occur. The plant superintendent entered the room, removed the plastic bottle from the tank, and placed it on the floor where it can be seen in the slide. He turned off the electrical stirrer and immediately left. The electrical stirrer severely distorted the top surface of the liquid. This distortion was worth $2 \%$ in reactivity. Just after he had gone out the door, which was about 15 feet away from the mixing tank, a second excursion resulted from the flattening of the top surface of the liquid in the tank. This excursion had an order of magnitude lower yield - about $2 \times 10^{16}$ fissions. This is due to the presence of a precipitate, sodium uranyl carbonate, which formed after the first excursion from a chemical reaction between the uranyl nitrate and sodium carbonate. These precipitate particles served as nucleation sites for the radiolytic gas and produced steam by local boiling in their vicinity. Without this precipitate a more severe excursion would have occurred. The settling of this precipitate to the bottom of the tank permanently terminated the excursion.

The supervisor and plant superintendent were both about 15 feet from the tank. The plant superintendent was shielded by a 12 inch hollow, concrete block wall. 
Both men then went downstairs and attempted to drain the tank by means of this hose, which you can see here, attached to a valve on the bottom of the tank. Precipitate was clogging this 1/2 inch drain line and, therefore, the superintendent returned to the third floor and restarted the electrical stirrer. Because some of the uranium precipitate had entered the drain pipe and more soon followed when the pipe was cleared and because the stirrer was operating, the tank did not go critical for a third time. The superintendent returned to the first floor and assisted the supervisor in draining the remaining solution.

There was no visible manifestation of the second excursion. Its existence is deduced from data showing that the two men were exposed to neutron radiation. This fact was not firmly established until several weeks after the incident occurred.

I now want to address your attention to the dosimetry problems relating to the man who died and the two survivors. The dead man was close to the tank and received such enormous doses of gamma radiation that film badge dosimetry was out of the question. The only data that one could work with was the neutron data, from which one could deduce the gamma ray exposure. The case of the survivors was complicated because only one man was wearing a film badge; the other was wearing only an indium foil. By the time it was known or suspected that they had been exposed to neutrons, the usual indium activity induced by epithermal neutrons had long since decayed away, and the only activity remaining was that induced by thermal neutrons. 
Slide 2 shows the neutron doses that we finally determined. As you can see, for the deceased operator the dose determined by activation of blood sodium is in agreement with the dose determined by activation of sulphur in the hair. Analysis of pubic hair gave 10,000 rad, and analysis of head hair gave 2500 rad. These fast neutron activations are consistent with a whole body dose of $5100 \mathrm{rad}$ as determined by blood sodium.

However, blood sodium activation gives for the superintendent and supervisor neutron doses of about 2 to 5 rad, whereas hair activation gives 60 to $80 \mathrm{rad}$. The RBE for this spectrum is 8.3. Consequently, the difference between these two estimates is critical. Additional data were needed to decide between these two methods. It was for this reason that we used dosimetry based on thermal neutron activations. Materials involved were all on the surface of the body. These were: a silver dollar in the hip pocket, 2 dimes in the pants pocket, and chromium in the stainless steel watch case.

I am sure that you are all aware of the problem in trying to make use of thermal neutron activation data. The albedo - or reflection coefficient for thermal neutrons - is about 8/10 for water and for the human body, and nearly that for other materials, such as walls. For this reason thermal fluxes can be an order of magnitude or so higher than one would calculate from a simple $\frac{1}{r^{2}}$ kind of attenuation. It would certainly seem at first that one would be better of $f$ basing all dosimetry estimates on data from fast neutron reactions. However, this is not always possible. Unless specially designed neutron flux monitors have been stationed 
in the area, it is difficult to obtain fast neutron data that is easy to analyze. Accidents occur in unlikely places and in the absence of special monitors one must use whatever materials are fortuitously on hand. These are likely to be heavily contaminated with fission products. By the time a thorough decontamination is carried out, the isotopes of short half-life have decayed.

The analysis of fast neutron activations is more difficult. Fast neutron cross sections are known with less accuracy than thermal neutron cross sections and are 10 to 100 times smaller. In addition, the analysis depends sensitively on the neutron spectrum. The reactions are threshold type and vary strongly with energy. Hence, the activation cross section used to interpret the data must be averaged over the correct spectrum for the particular accident. This effect is illustrated in the next slide. This shows the average cross sections for sulphur, nicke1, and iron ( $n, p)$ reactions. The first line gives the average over the fission spectrum, which is what is frequently reported in the literature. The second gives the average over the leakage spectrum from the vessel in which criticality occurred at Wood River Junction. This was calculated by detailed Monte Carlo methods. Reactivity codes which use a 20 or so neutron groups do not give enough detail in the higher energy portion of the spectrum to obtain an accurate average.

You can observe differences as large as a factor of two. When dealing with doses of around $100 \mathrm{R}$, a factor of two either way is very important. If we had used the fission spectrum average, our estimates of doses due to fast neutrons would have been only half as large. 
So, it is sometimes necessary to use thermal neutron activation data to supplement fast neutron data because the thermal cross sections are larger, they are known more accurately, and because to use fast neutron activation data a detailed knowledge of the neutron spectrum is needed in order to compute effective cross sections.

In using thermal activation data, we ran into two problems which merit some discussion. They might be termed the "near" and "far" effects. The man who caused the criticality was close enough to the vesse 1 to affect the neutron properties of the system. How should one take account of the human body? The next slide shows the system idealized for criticality calculations.

The man's body acts as a reflector, moderating some of the neutrons and returning them to the multiplying system. For one-dimensional criticality calculations, the man is taken as a cylindrical or spherical shell surrounding the tank and shown dashed on the slide. In order to compute the neutron dose, we take the incident neutron current times a conversion factor which converts neutron current to dose. The model used in the calculation affects the estimate of both the current density and the conversion factor.

First, consider the conversion factor which depends sensitively on the spectrum. We performed three calculations. In the first, the man's body is ignored; a bare system is calculated. In the other two, the man's body is taken to surround completely the critical vessel. In one case there is a $30 \mathrm{~cm}$ gap as shown on the slide. In the other, he is right against the tank; there 
is no gap. The conversion factor from current to dose depends on the spectrum. (Because the man subtends only a small angle, the bare calculation gives an accurate spectrum and conversion factor.) Slide 5 shows this effect. The bare spectrum, being the hardest, gives the largest dose for a given total current. The man in contact softens the spectrum the most and gives the smallest dose. Letting the man's body surround the tank produces a large over estimate of the spectral effect.

We next consider estimating the total incident current from thermal activation of material on the surface of the body, such as coins in the pocket or a belt buckle. Now in the Rhode Island accident, $80 \%$ of the neutron dose was produced by neutrons above $1 \mathrm{Mev}$. In determining the neutron current above $1 \mathrm{Mev}$ by measurements of thermal neutrons, extreme caution is needed. The arithmetic involved is shown on slide 6 .

The neutron dose is calculated by multiplying the incident neutron current by a conversion factor, which we have already discussed. If the fraction of neutrons which are thermal is well known, then the incident current can be determined by a knowledge of the incident thermal neutron current. Thermal activation measurements determine the thermal flux which is made up of the incident thermal current, the reflected thermal current, and a contribution from fast neutrons which are slowed down to thermal in the body and which leak out as thermal neutrons. In the Rhode Island accident, these three contributions to the thermal flux were about the same and so all of them had to be calculated accurately; none could be ignored.

As I said earlier, the thermal fraction is best calculated 
from the bare case. But the number of fast neutrons moderated in the body to thermal and leaking out must be calculated using some man model. One difficulty is shown on the next slide. A fast neutron is shown being moderated in the reflector and contributing to the thermal activation of the sample on the surface of the body. Actually that reflector doesn't exist and a spurious low energy neutron is counted. You will notice that this error is reduced when there is no gap at a11. So the bare calculation is best for the spectrum, and the one with no gap gives the best result for the moderation effect. An accurate moderation result was achieved by extrapolating from all three calculations.

The neutron doses resulting from the different models are shown in slide 8 .

Again we see that careful calculations yield a dose which is two or three times as large as one would get from straight, multigroup neutron methods.

The use of thermal activation data from samples far from the critical vessel presents different problems. The superintendent and supervisor were 15 feet from the assembly during the second excursion. At this distance the geometry is simple and they clearly are too far away to affect the spectrum emanating from the assembly. However, at this distance, fast neutron fluxas were so low as to lead to inconsistent results and it was again necessary to use thermal activation data.

The problem here was the increase in thermal flux resulting from reflections from the walls, floor, and ceiling in addition to the reflection and moderation from the human body. This 
problem was tackled empirically. The next slide shows the ratio of thermal flux to flux above $3 \mathrm{Mev}$ as determined experimentally for several distances. The calculated ratio in the leakage spectrum is 0.66 . The last column shows the increase in thermal flux over this value resulting from reflection as determined by measurements on isolated, metallic samples. (The body will shield a sample on its surface from half of the reflected neutrons. Hence in analyzing data for such samples, one-half the enhancement factor shown was used.)

Dose estimates obtained from thermal neutron activation measurements, after corrections for the effects discussed here today, were in good agreement with those estimated by blood sodium activation. In summary, one can obtain good estimates of dose from activation data provided one evaluates properly the factors shown in the next slide.

I have already discussed today the importance of the first 5 factors shown on the slide. The importance of the other 2 is obvious but worth reminding you of. The self-shielding of an object as thin as a dime is important in dealing with thermal neutrons. Activation measurements determine the neutron flux. However, it is the neutron current which we relate to dose. We need to know the cosines of the incident angles for neutrons in order to relate flux to current.

In conclusion, I would like to remind you that the use of radioactive sodium in the body to determine the incident neutron current is a very powerful method. Although the activation is produced by thermal neutrons, the method does not suffer 
from the problems discussed today. Most of the sodium activations are caused by fast neutrons which are slowed down in the body, and the probability of a fast neutron being captured in the body as a thermal neutron is insensitive to neutron energy, and hence to neutron spectrum, over wide limits. Close to the source, thermal neutrons contribute relatively little to the sodium activation and hence, accurate treatment of the thermal neutrons is not necessary.

The neutron doses determined are summarized in the last slide. Agreement of the methods is good for the operator. However, the discrepancy between the blood sodium and hair activation data for the other two men was serious. Additional data to resolve the discrepancy was essential. The thermal activations of surface samples provided these data and confirmed the blood sodium results.

The thermal activation data discussed here today represent only a small portion of the physics results. I wish to emphasize the difficulty in using thermal neutron data by pointing out that most of the physics effort was spent in this area. 


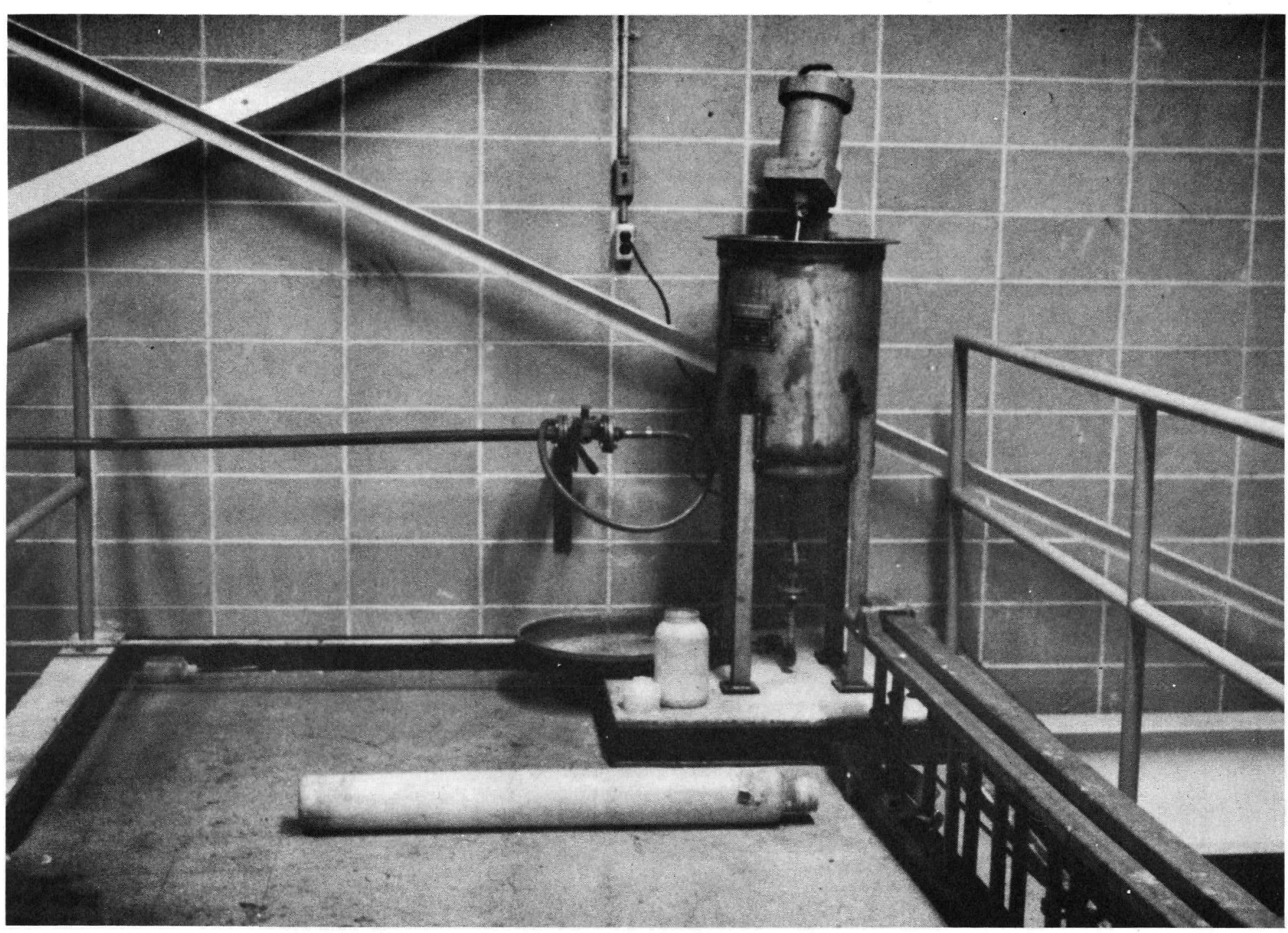


SUMMARY OF NEUTRON DOSES, rad

Operator

5100

Sodium Activation

Surface Samples, thermal

In foil

Ag dollar

Ag dime

Cr watchcase
3500

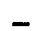

-

-
Superintendent

2.4

1.2

4.6

5.4

$-$

Supervisor

5.4

Hair (Fast Activation) $2500-10,000$

61.0

82.0

(slide 2) 
EFFECTIVE ACTIVATION CROSS SECTIONS

$$
\mathrm{S}^{32}(\mathrm{n}, \mathrm{p}) \mathrm{P}^{32} \quad \mathrm{Ni}^{58}(\mathrm{n}, \mathrm{p}) \mathrm{Co}^{58} \quad \mathrm{Fe}^{54}(\mathrm{n}, \mathrm{p}) \mathrm{Mn}^{54}
$$

Average over

Fission Spectrum

$57 \mathrm{mb}$

$115 \mathrm{mb}$

$101 \mathrm{mb}$

Average over

Accident Spectrum

45

60

49

(slide 3) 


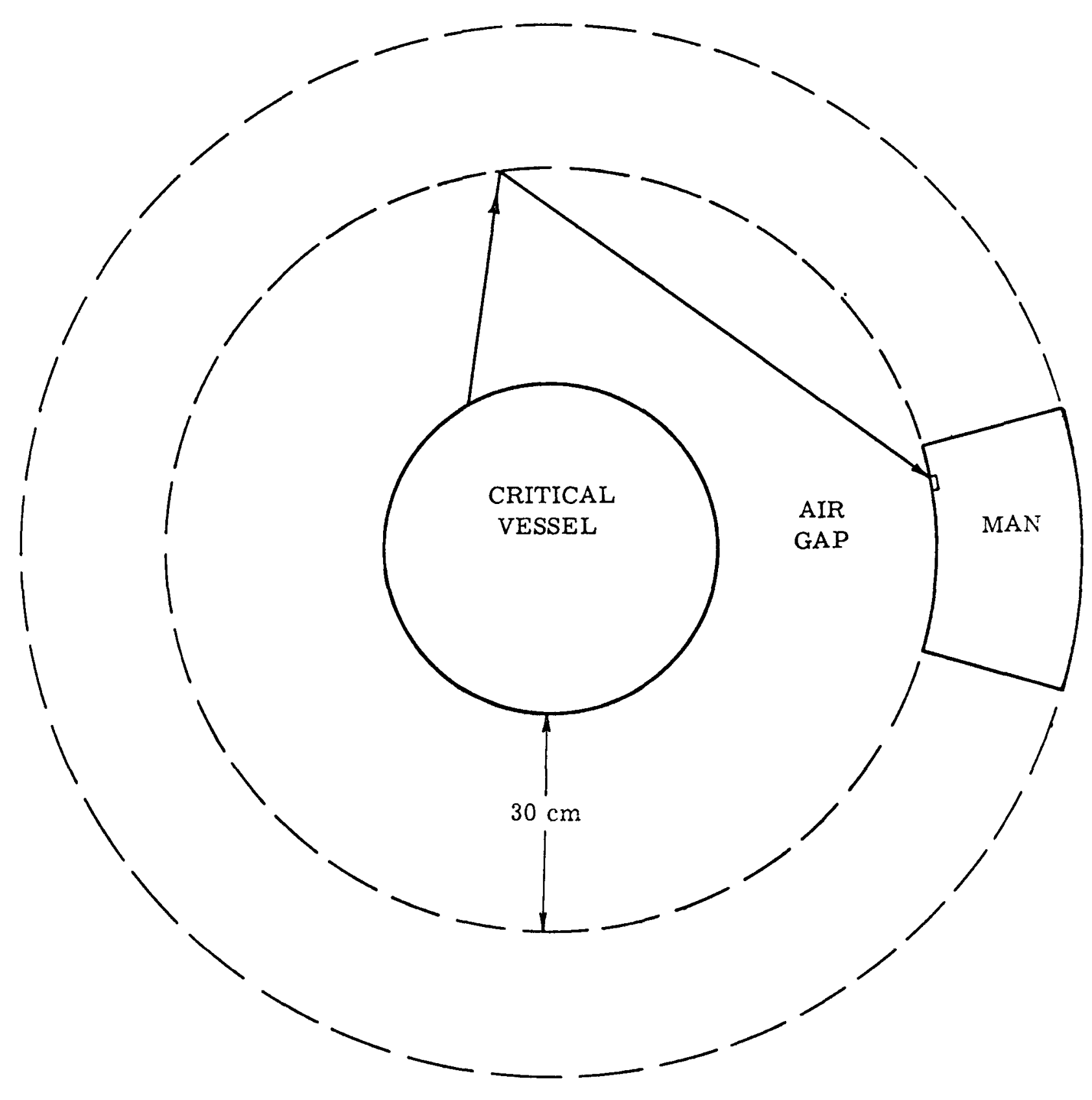

IDEALIZED GEOMETRY

UNC

(slide 4) 
EFFECT OF SPECTRUM ON CONVERSION FACTOR

Dose for Unit Current, $\mathrm{rad} /\left(\mathrm{n} / \mathrm{cm}^{2}\right)$

Bare assembly

$30 \mathrm{~cm}$ gap.

Contact; no gap
$1.56 \times 10^{-9}$

$1.26 \times 10^{-9}$

$1.04 \times 10^{-9}$

(slide 5) 
Neutron dose $=$ incident current $x$ conversion factor

Incident thermal neutron current $=$ incident current $x$ thermal fraction

$\begin{aligned} \text { thermal flux }= & \text { incident thermal current }+ \\ & \text { reflected thermal current }+ \\ & \text { fast neutrons moderated to thermal }\end{aligned}$ UNC

(slide 6) 


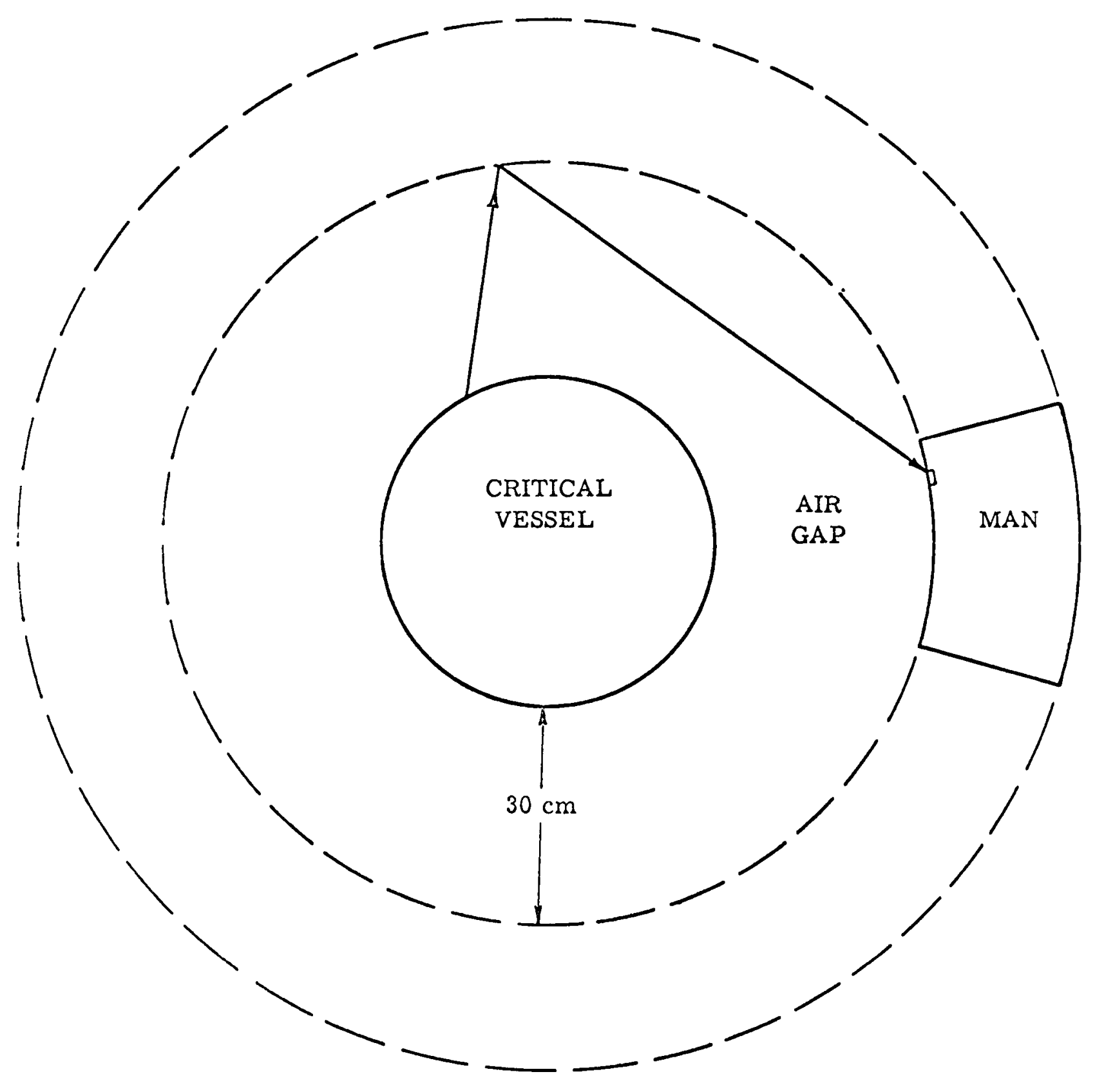

IDEALIZED GEOMETRY

(slide 7) 
EFFECT OF MODEL ON NEUTRON DOSE

\section{CORRECTION FACTORS}

\section{Dose \\ Conversion}

Accurate model

$30 \mathrm{~cm}$ gap

Contact; no gap
1

.81

.67
Incident

Current Density

1

.62

.53
Total

1

.50

.36

UNC

(slide 8) 


\section{EFFECT OF DISTANCE ON SPECTRUM}

Distance

9 in.

18 in.

183 in.

\section{Ratio of Thermal Flux} to flux above $3 \mathrm{Mev}$

1.82

2.84

15.20
Enhancement of thermal flux

2.75

4. 30

23.00

(s1ide 9) 


\section{NECESSARY INGREDIEN'TS FOR USING}

THERMAL ACTIVATIONS

Thermal activation cross sections

Non-thermal contributions to thermal activations Thermal reflection coefficient (albedo)

Enhancement factor for thermal neutrons

Neutron spectrum incirnnt on the body

Self-shielding factor:

Average cosine of neut. incidence angle

(s1ide 10) 
SUMMARY OF NEUTRON DOSES, rad

Operator Superintendent Supervisor

Sodium Activation

5100

2.4

5.4

Surface Samples, thermal

In foil
$\mathrm{Ag}$ dollar
$\mathrm{Ag}$ dime
$\mathrm{Cr}$ watchcase

3500

1.2

2.0

-

4.6

5.4

$-$

$-$

-

-

5.7

Hair (Fast Activation) 2500-10,000

61.0

82.0

(slide 11) 